\title{
Study on stability analysis of gravity wharf structure in Fujian
}

\author{
Jiaying Zhang ${ }^{1,2,3^{*}}$, Bin $\operatorname{Li}^{1,2,3}$ \\ ${ }^{1}$ CCCC Tianjin Port Engineering Institute Co., Ltd., Tianjin 300222, China \\ ${ }^{2}$ Key Laboratory of Port Geotechnical Engineering of Ministry of Communication, Tianjin 300222, China \\ ${ }^{3}$ Key Laboratory of Geotechnical Engineering of Tianjin, Tianjin 300222, China
}

\begin{abstract}
Gravity wharf is a common structure form in port engineering, and it is appropriate for rock foundation or the area of shallow buried bearing stratum. In this paper, stability analysis of gravity wharf and breakwater structure under seismic load in Fujian is studied, the potential factors of instability and corresponding repairing measures are put forward. These results have important significance to ensure the port operation safety and economize investment.
\end{abstract}

\section{Introduction}

The wharf construction is located in the southern coastal region of Fujian province. The bed rock is mainly Yanshanian granite, and the Quaternary overburden layer is composed of eluvium, alluvium and marine sedimentary strata. According to the investigation result, stratum structure in this area is very complex. Meanwhile, the wave is big, frequent and almost surge with long wavelength [1-2].

In April 2019, M 7 earthquake occurred in the surrounding waters nearby the wharf, when the project was just completed without operation. Considering the security aspects, stability analysis of gravity wharf has been carried out to determine the current status. Then potential factors of instability are discussed for providing reference of maintenance and reinforcement scheme.

\section{Project profile}

The wharf is gravity block structure, plane layout is jetty type, and breakwater is $400 \mathrm{~m}$ with long slope near outer sea. The length of wharf is $290 \mathrm{~m}$, and it has four berths of 500t. The designed top of wharf is $+6.0 \mathrm{~m}$, the bottom elevation of wharf apron is $-5.6 \mathrm{~m}$, and the bottom elevation of rubble bed is $-8.0 \mathrm{~m} .10-300 \mathrm{~kg}$ rubble is dump-filled behind the wharf as core stone of the breakwater, and 9t accropodes are placed on the surface of breakwater as armor block. The structure schematic drawing is shown in figure 1.

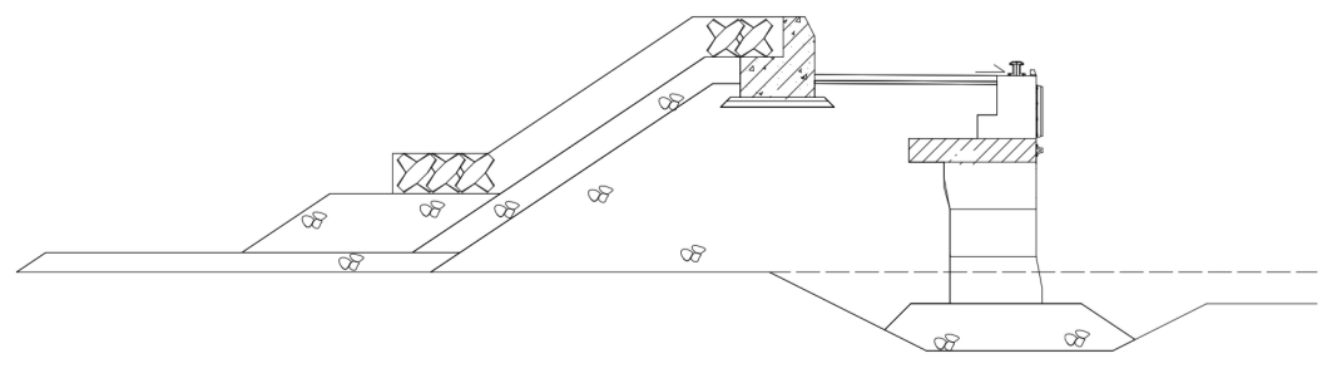

Figure 1. Structure schematic drawing.

\section{Analysis of gravity wharf structure}

\subsection{Calculation parameters}

The Foundation of Port Engineering Calculation System is used for stability analysis. Calculation is based on wharf structure design code (JTS 167-2018), load code for harbour engineering (JTS 144-1-2010), water transportation engineering seismic design code (JTS 1462012), and water transportation engineering foundation design code (JTS 147-2017).
The seismic intensity could be considered as 7 degree while considering horizontal seismic load, and seismic acceleration is $0.15 \mathrm{~g}$. According to the site investigation result of wharf, soil under structure is divided into many layers. The main parameters of each soil layer are shown in table 1. 
Table 1. Summary sheet of calculation parameters of each soil layer.

\begin{tabular}{cccccc}
\hline Number & Type & $\begin{array}{c}\text { Density } \\
\left(\mathrm{kN} / \mathrm{m}^{3}\right)\end{array}$ & $\begin{array}{c}\text { Undersea density } \\
\left(\mathrm{kN} / \mathrm{m}^{3}\right)\end{array}$ & $\begin{array}{c}\text { Cohesion } \\
(\mathrm{kPa})\end{array}$ & $\begin{array}{c}\text { Friction angle } \\
\left({ }^{\circ}\right)\end{array}$ \\
\hline 1 & Concrete & 24 & 14 & 999 & 45 \\
2 & Aggregate & 18 & 11 & 0 & 40 \\
3 & Aggregate & 18 & 11 & 0 & 40 \\
4 & Clay & 18 & 8 & 34.2 & 3.6 \\
5 & Clay & 18.2 & 8.2 & 34.2 & 3.6 \\
6 & Clay & 18.2 & 8.2 & 34.2 & 25.5 \\
7 & Sand & 20.6 & 10.6 & 11.1 & 34.1 \\
8 & Sand & 18.6 & 8.6 & 3.3 & 14 \\
9 & Clay & 18.4 & 8.4 & 29 & 21.8 \\
\hline
\end{tabular}

The theoretically lowest tide level in this area is $1.68 \mathrm{~m}$ below the elevation datum, and it is considered as the tide level datum of this structure. Three conditions are considered in calculation, as extreme low water level, design high water level and design low water level. And the water levels are $-0.43 \mathrm{~m}$ (return period is extreme low water level of 50 years), $3.72 \mathrm{~m}$ (high-tide cumulative frequency is $10 \%$ ), and $0.38 \mathrm{~m}$ (low-tide cumulative frequency is $90 \%$ ).

\subsection{Results}

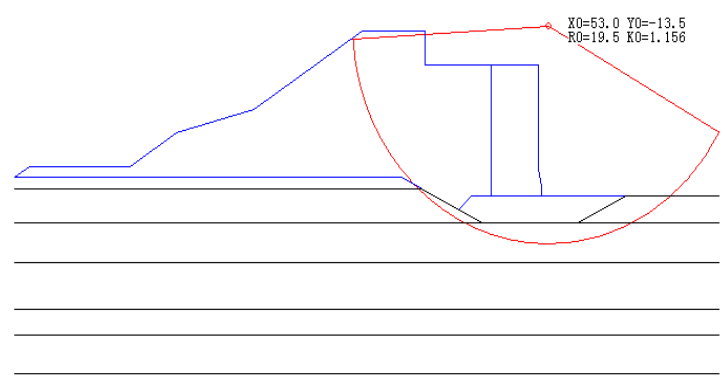

(b) extreme low water level with seismic loading

(a) extreme low water level without seismic loading

Figure 2. Results of wharf structure stability calculation at typical working conditions.

Table 2. Stability safety factor of wharf structure.

\begin{tabular}{cccc}
\hline $\begin{array}{c}\text { Working } \\
\text { condition }\end{array}$ & $\begin{array}{c}\text { Extreme low } \\
\text { water level } \\
\text { condition }\end{array}$ & $\begin{array}{c}\text { Design low } \\
\text { water level } \\
\text { condition }\end{array}$ & $\begin{array}{c}\text { Design high } \\
\text { water level } \\
\text { condition }\end{array}$ \\
\hline $\begin{array}{c}\text { Normal } \\
\text { condition } \\
\text { Seismic } \\
\text { condition }\end{array}$ & 1.235 & 1.246 & 1.313 \\
\hline
\end{tabular}

According to the shape of sliding surface in figure 2 , the third clay layer is the potential slip surface of natural foundation. Results in table 2 shows that stability under the condition of extreme low water level is the lowest. The minimum safety factor is 1.235 without seismic loading, and the minimum safety factor is 1.156 with seismic loading. The results meet the requirement of the minimum resistance coefficient in the design code of foundation for water transportation engineering.

\section{Analysis of stabilities against sliding and overturning of gravity wharf structure}

\subsection{Calculation parameters}

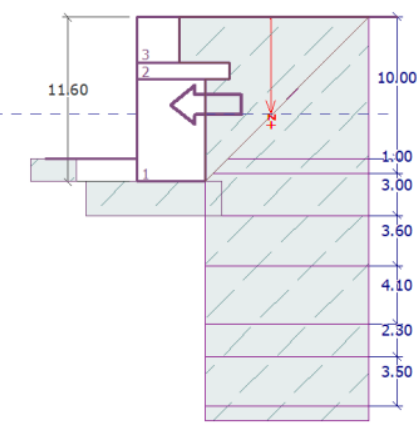

Figure 3. The profile of structure. 
GEO5 software is used to calculate the anti-overturning and anti-sliding stability of the wharf, structure profile is shown in figure 3, and the section 1, 2 and 3 in the figure are concrete structure. The depth of groundwater inside and outside of structure is $6.43 \mathrm{~m}$ (extreme low water level condition). The rock and soil at the bottom of the structure is impermeable, and the ground uplift caused by water level difference is not considered. The seismic intensity is considered as 7 degree $(0.15 \mathrm{~g})$, comprehensive horizontal seismic coefficient $a_{w}$ is 0.038 , seismic angle $\theta$ is $2.30^{\circ}$, Importance coefficient of seismic action $C_{i}$ is 1.00 , water under the groundwater level is free water, underwater seismic angle $\theta^{\prime}$ is $3.8^{\circ}$, adjustment coefficient of foundation seismic bearing capacity $\zeta_{a}$ is 1.30 . The other detailed parameters are shown in table 3 .

Table 3. Calculation parameters summary sheet of geotechnical materials.

\begin{tabular}{ccccccc}
\hline Number & Type & $\begin{array}{c}\text { Density } \\
\left(\mathrm{kN} / \mathrm{m}^{3}\right)\end{array}$ & $\begin{array}{c}\text { Undersea } \\
\text { density } \\
\left(\mathrm{kN} / \mathrm{m}^{3}\right)\end{array}$ & $\begin{array}{c}\text { Cohesion } \\
(\mathrm{kPa})\end{array}$ & $\begin{array}{c}\text { Friction } \\
\text { angle } \\
\left({ }^{\circ}\right)\end{array}$ & $\begin{array}{c}\text { Friction angle } \\
\text { of structure } \\
\text { and soil } \\
\left({ }^{\circ}\right)\end{array}$ \\
\hline 1 & Backfilling stone & 25.00 & 16.00 & 0.00 & 40.00 & 35.00 \\
2 & Muck & 18.00 & 8.00 & 34.00 & 3.60 & 3.60 \\
3 & Silt & 18.00 & 8.00 & 11.10 & 25.50 & 25.50 \\
4 & $\begin{array}{c}\text { Sand with clay } \\
\text { Partly weathering } \\
5\end{array}$ & 18.60 & 8.60 & 3.30 & 34.10 & 34.00 \\
6 & $\begin{array}{c}\text { Completely } \\
6\end{array}$ & 18.40 & 8.60 & 29.00 & 14.00 & 14.00 \\
\hline
\end{tabular}

\subsection{Results}

1) Anti-overturning moment is $4596.79 \mathrm{kNm} / \mathrm{m}$, overturning moment is $1334.30 \mathrm{kNm} / \mathrm{m}$, and safety factor is $3.45>1.60$. The checking of anti-overturning capability can meet the requirement.

2) Anti-sliding force (Parallel to the basement) is $1227.84 \mathrm{kN} / \mathrm{m}$, sliding force is $301.77 \mathrm{kN} / \mathrm{m}$, and safety factor is $4.07>1.30$. The checking of anti-sliding capability can meet the requirement.

3) Subgrade bearing capacity is $515.97 \mathrm{kPa}$, the maximum basement stress is $168.33 \mathrm{kPa}$, therefore, vertical bearing capacity checking can meet the requirement.

4) Eigenvalue of horizontal bearing capacity is $518.29 \mathrm{kN}$, the maximum horizontal load is $301.77 \mathrm{kN}$, safe factor is $1.72>1.30$, horizontal bearing capacity checking (without considering lateral pressure) can meet the requirement.

5) Foundation settlement is $177.5 \mathrm{~mm}$, foundation deformation calculation depth is $17.19 \mathrm{~m}$, rotation angle of width direction is 2.361( $\tan * 1000)$.

According to the calculation results, the antioverturning capability and anti- sliding capability of wharf structure can meet the needs.

\section{Potential factors of instability}

1) Destruction of armor block and breakwater caused by wave action.

Partial accropodes are near the area of strong wave. Because the wave is overtopping, the slope shoulder made of dump-filled stone can be influenced by wave force frequently. That causes the stones slipping and the anti-wave capacity of breakwater reducing. The whole structure safety is under threat.

2) Damage of wharf structure caused by foundation deformation.

Partial foundation silt clay layer is thick, it can bring out large settlement, differential settlement, incline and partial incline in using. When the deformation is greater than the allowable deformation of foundation, the normal use of wharf will be affected even endanger the safety of the structure.

3) Risk of sand liquefaction by earthquake.

According to the exploration result, saturated silty sand and medium sand layers exist within $20 \mathrm{~m}$ depth, and the judgement of saturated sand liquefaction as 7 degree. After evaluation of liquefaction, the silty sand and medium sand layers are both slightly liquefaction soil layer. According to the water transportation engineering seismic design code (JTS146-2012), there are liquefiable soil layers in the field, and it is seismic adverse site [3-5].

\section{Measures of improving structure stability}

1) Artificial block should be added at slope shoulder, bottom protection stone and armor block can be dumped filling if necessary. Meanwhile, to increase the stability of rubble-bedding in use, reduce slip moment and increase the anti-wave capacity, the slope offshore side could be slower.

2) Close monitoring of the structural deformation. Observation points of settlement displacement on wharf and breakwater should be set to monitor the stability of 
structure dynamically. Then according to the monitoring results, pertinence measures would be taken.

3) The berthing speed and maximum wind allowable for docking must be restricted strictly. The berthing and mooring that beyond design standard may cause the damage of structure.

4) Structure damage caused by violent earthquake is inevitable, the principles of improvement are reducing the dynamic earth pressure and filling the sand foundation sufficiently. The loss of sand causes inclination of wharf, therefore, a vertical nonrigid wall at bottom can prevent the loss of sand during the earthquake. To improve the seismic stability, sand under the base can be fully filled if necessary.

\section{Conclusion}

The stability of gravity wharf and breakwater structure under seismic load is calculated and analysed in this paper, and the results show that the whole structure is in the stable state. But it is necessary to monitor the deformation closely and use the structure according to design regulations strictly. Reinforcement and repair measures should be taken when necessary.

Evaluating the stability state of port structures scientifically and reasonably contributes to predict the remaining service life of the structure, also provide reference for the selection of reinforcement and repair measures. It is of great significance to ensure the safe operation of the port and save investment.

\section{References}

1. YIN Yong-xin, ZHANG Ao, GAO Ling-xiao. (2017) Damage of harbour and marine structure and reinforcement restoration. China Harbour Engineering, 37: 53-57.

2. CHEN Guo-yu, WANG Zhi, WANG Chao. (2017) Deformation detection and safety evaluation of a gravity wharf in Qingdao. China Water Transport, 17: $182-185$.

3. LI Nan, ZHANG Chun-mao. (2019) Analysis and treatment scheme of wharf bank slope instability of Makou dangerous section in the Yangtze River. China Water Transport, 19: 164-165.

4. ZHANG Hui-juan. (2019) Analysis of floating stability of gravity wharf caisson structure. Pearl River Water Transport, 6: 14-15.

5. GE Yun-jian. (2016) Analysis of anti-sliding and anti-tilting stability of gravity wharf. China Water Transport, 16: 202-203. 